\title{
CRIADOUROS DE IMATUROS DE MOSQUITOS (DIPTERA, CULICIDAE) INTRODUZIDOS EM MATA PRESERVADA NA ÁREA URBANA DE CURITIBA, PARANÁ, BRASIL ${ }^{1}$
}

\author{
Mario Antonio Navarro da Silva ${ }^{2}$ \\ Ana Leuch Lozovei ${ }^{3}$
}

\begin{abstract}
ImMATURE MOSQUitoes BREEDING (Diptera, CULICIDAE) PLACED INSIDE A PRESERVED FOREST IN THE URBAN AREA OF CURITIBA, PARANÁ, BRAZIL. Mosquitoes ecological features were studied in a preserved forest - Capão da Imbuia -placed in the urban area of Curitiba City, Paraná, Brasil. In this research were noted immature forms in artificial recipients made by different materials. Five species were found in this recipients: Culex (Culex) acharistus Root, 1927, Culex (Culex) group coronator Dyar \& Kanb, 1906, Culex (Culex) eduardoi Casal \& Garcia, 1968, Culex (Culex) quinquefasciatus Say, 1823 and Toxorhynchites (Lynchiella) theobaldi (Dyar \& Kanb, 1906). It's very important to know the mosquitoes that in urban area due they carry human desease agents by some species.

KEY WORDS. Culicidae, artificial recipients, ecology
\end{abstract}

As reservas florestais em áreas urbanas e periurbanas possuem três ambientes com características contrastantes - 0 interior da reserva com caráter próximo do silvestre, a borda circundante e a área contígua com estrutura urbanizada. São ambientes diferenciados que oferecem condições propícias aos culicídeos já urbanizados há algum tempo, aos mosquitos silvestres e também aos que estão em vias de assimilar comportamento ambivalente.

O estudo de culicídeos em reservas florestais em meio densamente povoado pode revestir-se de grande importância, uma vez que estas áreas podem abrigar grande diversidade de espécies de mosquitos, além de servir de abrigo para mosquitos adultos provindos de outras áreas.

Os recipientes de origem antrópica, eliminados na área urbana com capacidade de reter água, transformam-se em criadouros de culicídeos e representam grande risco, em consequência da procriação das espécies de culícideos vetores de agentes de doenças humanas e animais.

A quantidade e a diversidade deste tipo de resíduo gerado é muito elevado, principalmente quando o processo de urbanização não é acompanhado necessariamente de um adequado fornecimento dos serviços essenciais de saneamento básico

1) Contribuição número 978 do Departamento de Zoologia, Universidade Federal do Paraná.

2) Departamento de Zoologia, Universidade Federal do Paraná. Caixa Postal 19020, 81531-990 Curitiba, Paraná, Brasil.

3) Departamento de Patologia Básica, Universidade Federal do Paraná. Caixa Postal 19031, 81531-970 Curitiba, Paraná, Brasil. 
à população, assim como locais apropriados de destinação dos materiais descartados CURTIS \& FEACHEM (1981), BARRERA-RODRIGUEZ et al. (1979), BAUMGARTNER (1988) e LOPES et al. (1993).

Recipientes utilizados como criadouros de culicídeos foram considerados por diversos autores, o pneu, por exemplo, já foi referido por RACHOU et al. (1954), ForATTINI (1962), BOND \& FAY (1969), KEIRANS (1969), CHADEE et al. (1981), BAILEY et al. (1983), BEIER et al. (1983b), HARAMIS (1984), LUZ et al. (1987), ANDreadis (1988), Craven et al. (1988), NASCI (1988), GeTtMan \& Hall (1989), NAWROCKI \& GRAIG (1989), O’MEARA et al.(1989a).

LOPES et al. (1985a,b, 1987, 1993), FORATTINI \& RABELLO (1960), BARRERA-RODRIGUEZ et al. (1979), LOZOVEI \& LUZ (1976a), LOZOVEI \& LUZ (1976b), BARRERA-RODRIGUEZ et al. (1982), SILVA \& LOPES (1985), O'MEARA et al. (1992a e 1992b) e CHAHAD \& LOZOVEI (1994), fizeram referências a outros tipos de criadouros utilizados por mosquitos.

Com objetivo de estudar aspectos da ecologia de imaturos de culicídeos em artefatos antrópicos em locais de mata preservada dentro de área urbanizada da cidade de Curitiba, Paraná, foram introduzidos cinco diferentes tipos destes artefatos no interior e área adjacente da mata denominada Capão da Imbuia.

\section{MATERIAL E MÉTODOS}

O município de Curitiba localiza-se na porção centro-sul do primeiro planalto do Estado do Paraná, na porção oriental do Estado, estendendo-se de norte a sul, em forma de arco, com uma largura de 70 a $80 \mathrm{~km}$, limitando-se a leste pela serra do Mar e a oeste pela escarpa devoniana, nas coordenadas $25^{\circ} 25^{\prime} 04^{\prime \prime} \mathrm{S}$ e $49^{\circ} 14^{\prime} 30^{\prime \prime} \mathrm{W}$, e a uma altitude de $945 \mathrm{~m}$ (MAACK 1981).

Em relação ao aspecto climático, a cidade apresenta temperatura média anual igual a $16,5^{\circ} \mathrm{C}$. O mês de maior precipitação pluviométrica é janeiro com $190,7 \mathrm{~mm}$, e o menor é agosto com $78,2 \mathrm{~mm}$, sendo a média anual de $1.451,8 \mathrm{~mm}$. A média anual da umidade relativa do ar é igual a 81,5\% (MAACK 1981).

A área do Capão da Imbuia, onde o estudo foi levado a efeito, tem vegetação semelhante à primitiva que recobria esta região do Paraná. Conta com área de aproximadamente $32.000 \mathrm{~m}^{2}$, situado em bairro homônimo, a $10.000 \mathrm{~m}$ a leste do marco zero da cidade de Curitiba. Originalmente "capão", na acepção de MAACK (1981) identificava pequenas formações florestais, de formato arredondado, cercadas por vegetação aberta geralmente campo.

No início deste século a área ao redor do Capão da Imbuia era destinada à produção agrícola. Por volta de 1954 esta área passou para responsabilidade da Prefeitura Municipal de Curitiba, a qual deu início ao povoamento com aproximadamente dez famílias, preservando o capão de mata. Em 1990, segundo estimativa do Instituto de Pesquisa e Planejamento Urbano de Curitiba, contava com 28.000 habitantes, estando atualmente circundada pela estrutura urbana (Fig. 1).

A flora do Capão da Imbuia está classificada como floresta umbrófila mista de Araucária caracterizada pela presença de coníferas e folhosas. Apresenta três diferentes estratos, dos quais o primeiro é o de copas dominantes ocupado princi- 
palmente pelos pinheiros. O segundo estrato, co-dominante e intermediário, é ocupado também por pinheiros juntamente com imbuias, canelas pretas, quaiacás e carobas. O último estrato, dominado principalmente pelas mirtáceas, tem como exemplares característicos as pitangas e as guabirobas (DISPERATI \& JUNIOR 1988).

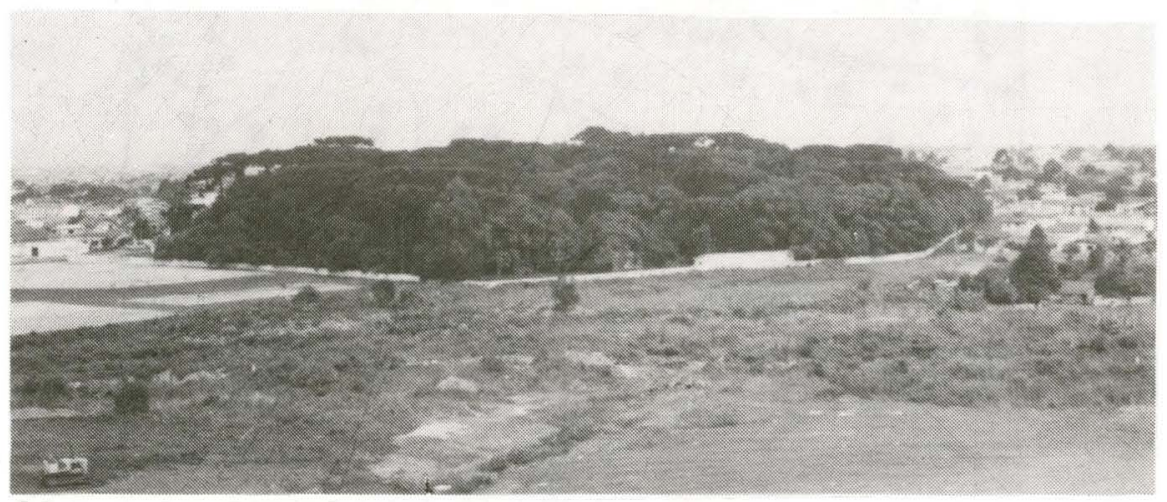

Fig. 1. Vista panorâmica geral do Capão da Imbuia, Curitiba, Paraná.

Segundo DomBRowsKi \& KUnIYOSHI (1967), as árvores de grande porte pertencem às seguintes espécies: Araucaria angustifolia (Bert.) O. Ktze (Araucariaceae) pinheiro do Paraná; Ocotea porosa (Nees \& Mart.) Barroso (Lauraceae), imbuia ou canela imbuia; Ocotea puberula (Rich.) Nees (Lauraceae), canela guaiacá; Eugenia uniflora L. (Myrtaceae), pitanga; Podocarpus sellowii Klotz (Podocarpaceae). Também estão presentes os seguintes representantes da família Bromeliaceae: Aechmea distichantha Lem; Aechmea recurvata, (Klotzsch) L.B.Smith; Tillandsia usneoides, (L.), "barba de pau"; Tillandsia tenuifolia L. e Vriesia friburgensis Mez.

Para a coleta de imaturos de culicídeos foram instalados cinco diferentes tipos de recipientes: cerâmica, cimento-amianto, lata, plástico e pneu de automóvel. Utilizaram-se três repetições destes recipientes para cada conjunto. O arranjo do conjunto foi feito de modo que cada um deles continha três repetições dos diferentes recipientes, totalizando quinze elementos dispostos em três colunas, com espaçamento de $5 \mathrm{~m}$ entre as colunas e igualmente entre os recipientes afixados nas colunas, ocupando uma área total de $200 \mathrm{~m}^{2}$. Em pontos previamente demarcados de cada coluna, foram instalados cinco recipientes de diferentes naturezas, em sequência diferenciada nas três colunas, para que os do mesmo tipo não ficassem próximos. Instalaram-se dois conjuntos: um conjunto no interior da mata e o outro na área adjacente à mata. Estes dois conjuntos distavam entre si em aproximadamente $50 \mathrm{~m}$ (Figs 2-4).

Os recipientes de cerâmica, caracterizavam-se pela cor marrom com capacidade volumétrica máxima para $5.100 \mathrm{ml}$ de água, abertura superior de $23 \mathrm{~cm}$ de diâmetro e $20 \mathrm{~cm}$ de profundidade. Os de cimento-amianto, vasos de marca Eternit ${ }^{\circledR}$ 


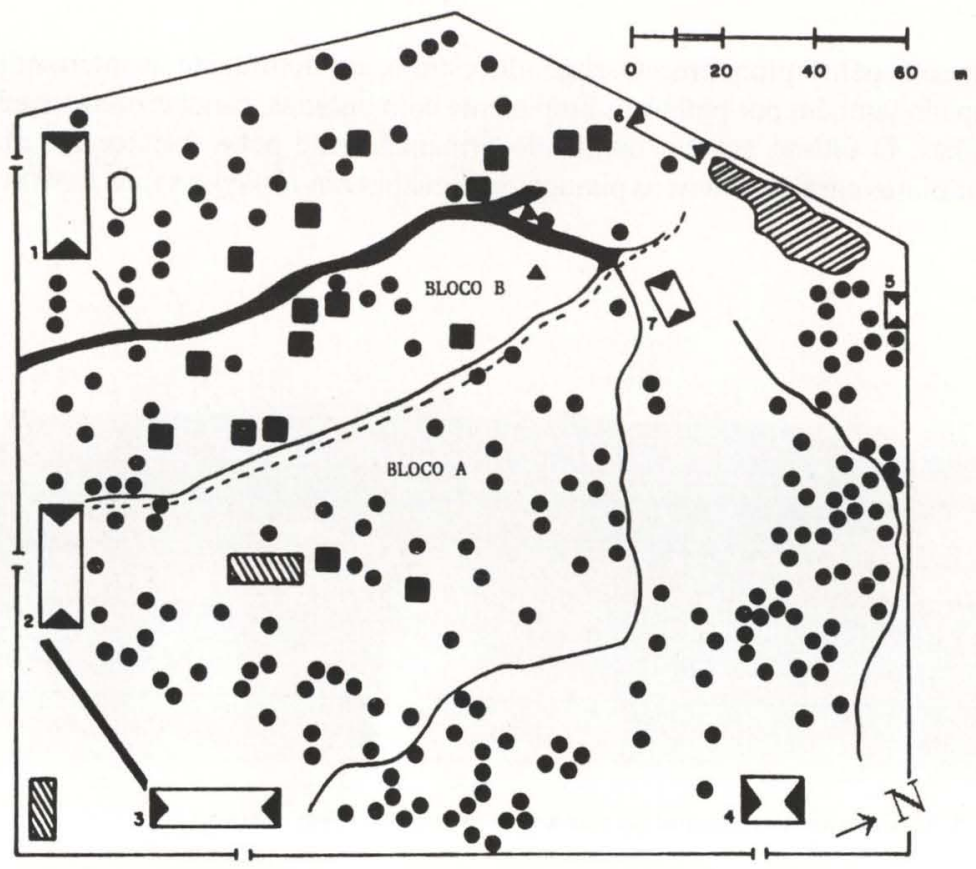

LEGENDA

- Pinheiro do Paraná

4 Canela

Imbuia

Recipientes artificiais

Serpentário
4 Construções

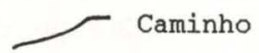

... Lina de Separação
de blocos

Estrada

Lago

Fig. 2. Aspecto e disposição dos elementos existentes e introduzidos na área pesquisada, Capão da Imbuia, Curitiba, Paraná. Esquema a partir de DISPERATI \& JUNIOR (1988).

na cor cinza, apresentavam abertura superior de $23 \mathrm{~cm}$ de diâmetro, profundidade de $17 \mathrm{~cm}$ e com capacidade máxima de retenção da água igual a $5.925 \mathrm{ml}$. Recipientes de lata -latas de conserva do extrato de molho de tomate, utilizadas após a retirada da tampa superior e limpeza - com capacidade máxima para 4.150ml de água, forma cilíndrica, com $15 \mathrm{~cm}$ de diâmetro e $22 \mathrm{~cm}$ de profundidade. Os de plástico cor branca, forma cilíndrica, diâmetro de $18 \mathrm{~cm}$, profundidade de $18 \mathrm{~cm}$ e capacidade 


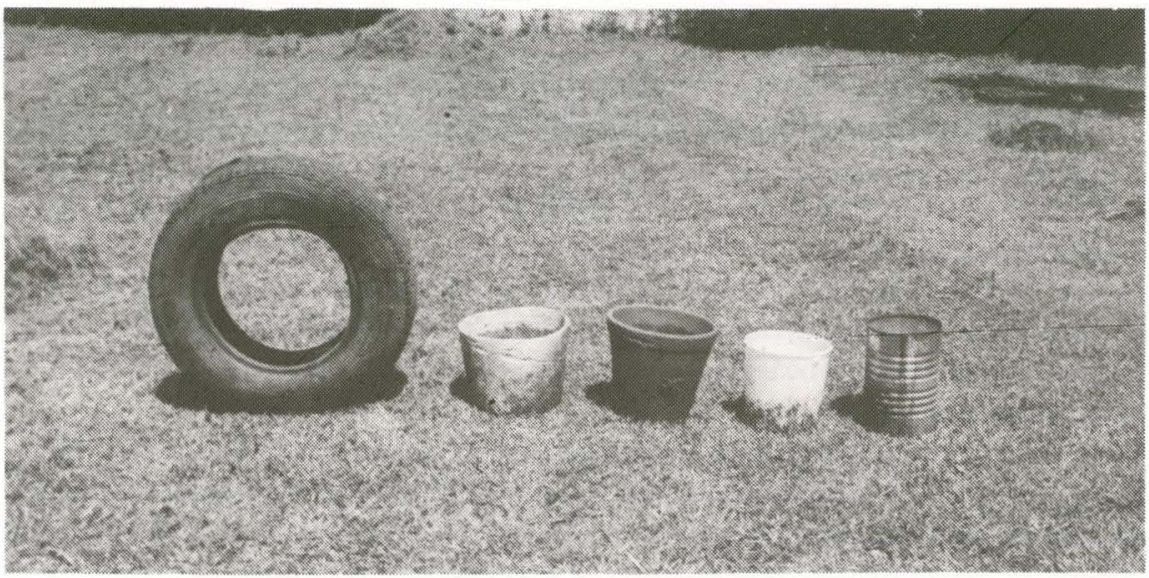

Fig. 3. Recipientes artificiais, da esquerda para direita: pneu de automóvel, cimento-amianto, cerâmica, plástico e lata, empregados na pesquisa, Capão da Imbuia, Curitiba, Paraná.

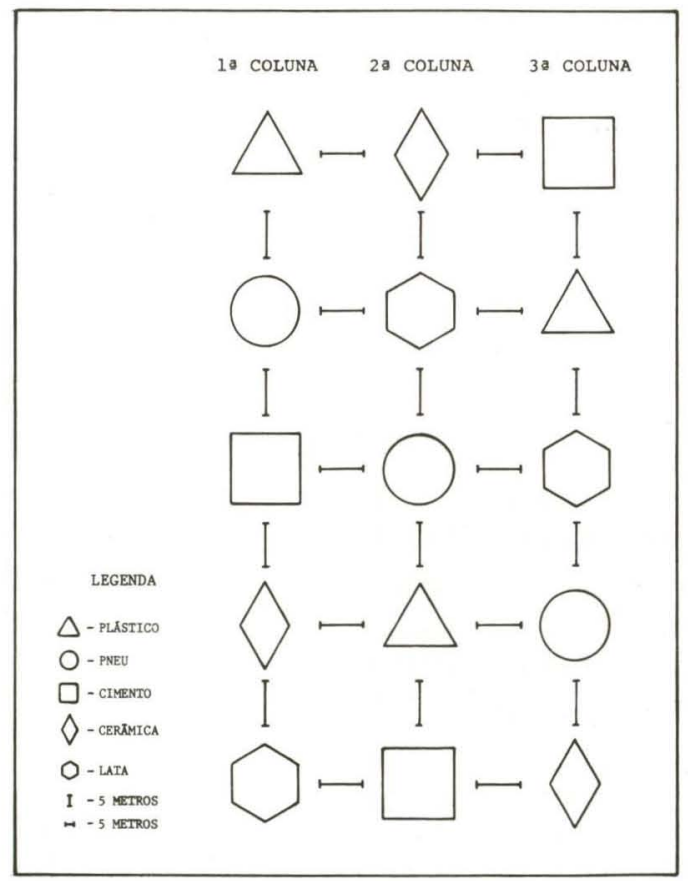

Fig. 4. Disposição e distanciamento entre os quinze recipientes artificiais introduzidos na área de pesquisa, Capão da Imbuia, Curitiba, Paraná. 
máxima de retencão de água de $3.300 \mathrm{ml}$. E ainda os pneus de automóvel foram instalados na posição vertical com auxílio de estacas de madeira. Nesta posição a capacidade máxima de retenção de água é de aproximadamente $3.100 \mathrm{ml}$ (Fig. 3).

Os recipientes artificiais, antes de sua instalação, receberam água destilada e ficaram em repouso no laboratório durante oito dias, protegidos de eventuais oviposições de culicídeos. Após este período os recipientes foram transportados ao Capão da Imbuia, fixados no solo até que ficassem com aproximadamente metade de sua altura acima da superfície. Os pneus não obedeceram a este padrão devido às suas características, permanecendo na posição de rolagem, amarrados a uma estaca de madeira. Por ocasião da instalação, cada recipiente recebeu $3.000 \mathrm{ml}$ de água de poço artesiano.

A coleta dos imaturos de culícideos ocorreu no período de março de 1990 a março de 1991. A cada quinze dias, a água de cada um dos recipientes era coada através de peneira, com abertura da malha de cerca de $200 \mu \mathrm{m}$ de diâmetro. Da peneira os imaturos de mosquitos eram tranferidos para frascos de vidro com capacidade para $300 \mathrm{ml}$ e transportados ao laboratório. A água resultante da filtração era recolocada no recipiente, completando-se o volume até $3.000 \mathrm{ml}$ com água de poço artesiano, caso fosse necessário.

Antes da coleta de amostras, para verificação da presença de mosquitos, alíquotas de $250 \mathrm{ml}$ de água foram retiradas de cada um dos trinta recipientes, para análise dos fatores físico-químicos, $\mathrm{pH}$ e turbidez. Para determinar o $\mathrm{pH}$ da água foi utilizado o aparelho Micronal modelo B-271 e para determinar a turbidez um turbidímetro Micronal modelo B-250 com unidade expressa em UNT (Unidade Nefelométrica de Turbidez). Estas análises foram realizadas no Laboratório de Análise Fisíco-quimíca da Água da Companhia de Saneamento do Paraná (SANEPAR).

Efetuou-se também a tomada da temperatura da água dos recipientes, em ambos habitats, com periodicidade quinzenal, em três horários ao longo de um dia às 9:00, 12:00 e às 15:00 horas. Para este procedimento utilizou-se termômetro Incoterm com escala de $-10^{\circ} \mathrm{C} \mathrm{a}+110^{\circ} \mathrm{C}$, mergulhando-o até metade de sua altura, na água, durante dois minutos. Convém ainda observar que, concomitantemente à realização da tomada da temperatura da água nos recipientes, procedia-se também a anotação da temperatura do ar, junto aos recipientes artificiais estudados.

No interior da mata foi tomada a temperatura da água em um recipiente de cada tipo, instalados na mesma coluna, devido à similaridade das condições a que estavam submetidos. Já na área adjacente à mata, devido às condições diferenciadas de sombreamento, foram obtidas as temperaturas dos recipientes instalados em duas colunas, as quais recebiam mais e menos horas de insolação ao longo do dia.

As planilhas de observações meteorológicas foram obtidas junto a Estação número 83842 do Instituo Nacional de Meteorologia, localizada no Campus Universitário do Centro Politécnico da Universidade Federal do Paraná. Esta estação situa-se nas coordenadas $25^{\circ} 26^{\prime \prime} \mathrm{S}$ e $49^{\circ} 16^{\prime \prime} \mathrm{W}$, a uma altitude de $923,50 \mathrm{~m}$, com distância aproximada de $3.900 \mathrm{~m}$, em linha reta, do Capão da Imbuia.

Para análise dos fatores ambientais, tais como: temperatura do ar, evapora- 
ção, precipitação pluviométrica e horas de insolação, adotou-se o período entre duas coletas sucessivas como base de cálculo, para obtenção das médias e somatórias dos dados meteorológicos. Calculou-se a média da temperatura média para os dias entre as coletas sucessivas, assim como as médias da temperatura máxima e miníma. Para precipitação pluviométrica, evaporação e horas de insolação, procedeu-se a somatória de cada um destes fatores, para o período entre duas coletas sucessivas.

$\mathrm{Na}$ identificação de larvas de quarto ínstar, exúvias larvares e pupais, genitálias masculinas e de adultos montados em alfinetes, seguiu-se as chaves dicotômicas de Forattini (1962, 1965a,b); DARSie (1985); LANE \& CERQueIra (1942). Utilizaram-se também as chaves elaboradas pelo Departamento de Epidemiologia da Faculdade de Saúde Pública da Universidade de São Paulo: 1) Chaves para identificação das subfamílias, tribos e gêneros de Culicidae da América; 2) Chaves para os subgêneros da América. Foram também utilizados os seguintes catálagos de mosquitos; KNIGTH \& STONE (1977); WARD (1984) e GAFFIGAN \& WARD (1985).

Após a identificação, uma parcela dos exemplares das espécies identificadas foram encaminhadas ao Dr. Oswaldo Paulo Forattini, da Faculdade de Saúde Pública da Universidade de São Paulo, para obter confirmação das espécies.

Exemplares de cada uma das espécies identificadas foram depositados na Coleção de Entomologia Pe. Jesus S. Moure do Departamento de Zoologia da Universidade Federal do Paraná.

Para análise estatística foram utilizados cálculos de médias para efeito de comparação e análise de variância para comparação dos fatores físíco-químicos da água entre os habitats estudados.

\section{RESULTADOS}

Dos conjuntos de recipientes introduzidos nos dois habitats, interior e área adjacente à mata, resultaram na coleta de 27.722 imaturos de culicídeos, sendo 7.474 $(27,00 \%)$ no primeiro habitat e $20.248(73,00 \%)$ no segundo. Em relação ao número de recipientes positivos para a presença de imaturos, os dois habitats analisados apresentaram percentuais de ocupação semelhantes. $\mathrm{O}$ interior da mata com 47,75\% (53 recipientes) e na área adjacente com 52,25\% (58 recipientes).

Ao total foram coletadas cinco espécies de Culicidae distribuídas em dois genêros: Culex (Culex) acharistus Root,1927, Culex (Culex) grupo coronator Dyar \& Knab, 1906, Culex (Culex) eduardoi Casal \& Garcia, 1968, Culex (Culex) quinquefasciatus Say, 1823 e Toxorhynchites (Lynchiella) theobaldi (Dyar \& Knab, 1906). Os números absolutos e percentuais de cada uma destas espécies nos habitats analisados encontram-se na tabela I.

Culex quinquefasciatus foi a espécie predominante em ambos os habitats analisados, perfazendo $93,43 \%$ do total. Os imaturos desta espécie foram coletados nos cinco diferentes tipos de recipientes tanto na área adjacente quanto no interior da mata, com exceção dos recipientes de plástico no interior da mata (Tab. I).

Nos pneus introduzidos no interior e na área adjacente à mata foram coletados imaturos em quantidade e frequência superiores aos demais recipientes. 
Tabela I. Ocorrência das espécies e o número de imaturos nos cinco diferentes tipos de recipientes artificiais instalados no interior e área adjacente à mata, de março de 1990 a março de 1991, Capão da Imbuia, Curitiba, Paraná.

\begin{tabular}{|c|c|c|c|c|c|c|c|c|c|c|c|c|c|c|}
\hline \multirow{3}{*}{ Espécies } & \multicolumn{14}{|c|}{ Recipientes artificiais } \\
\hline & \multicolumn{7}{|c|}{ Interior da mata } & \multicolumn{7}{|c|}{ Área adjacente à mata } \\
\hline & $\mathrm{CE}$ & $\mathrm{CM}$ & LT & $\mathrm{PL}$ & PN & Total & $\%$ & CE & $\mathrm{CM}$ & LT & $\mathrm{PL}$ & $\mathrm{PN}$ & Total & $\%$ \\
\hline Culex (C.) quinquefasciatus & 991 & 590 & 28 & 0 & 497 & 76579 & 88,02 & 359 & 124 & 163 & 182 & 193222 & 20150 & 99,52 \\
\hline Culex (C.) grupo coronator & 0 & 0 & 0 & 0 & 39 & $9 \quad 39$ & 0,53 & 40 & 0 & 51 & 0 & 7 & 98 & 0,48 \\
\hline Culex (C.) eduardoi & 411 & 80 & 0 & 0 & 167 & 7658 & 8,80 & 0 & 0 & 0 & 0 & 0 & 0 & 0,00 \\
\hline Culex (C.) acharistus & 111 & 9 & 0 & 0 & 71 & 191 & 2,56 & 0 & 0 & 0 & 0 & 0 & 0 & 0,00 \\
\hline Toxorhynchites (L.) theobaldi & 0 & 0 & 0 & 0 & 7 & 7 & 0,09 & 0 & 0 & 0 & 0 & 0 & 0 & 0,00 \\
\hline Total & 1433 & 679 & 28 & 0 & 5254 & 47474 & 100,00 & 399 & 124 & 214 & 182 & 193292 & 20248 & 100,00 \\
\hline
\end{tabular}

(CE) Cerâmica, (CM) cimento-amianto, (LT) lata, (PL) plástico, (PN) pneu, (\%) porcentagem da espécie sobre o total de imaturos.

Em relação à diversidade, no interior da mata o pneu foi o recipiente explorado por maior número de espécies; já na área adjacente foi detectada a presença das mesmas espécies, porém coletadas nos recipientes de cerâmica e lata (Tab. I).

Os demais recipientes artificiais testados, foram colonizados por culicídeos em frequência e quantidade inferiores ao detectado para os pneus. O número de espécies que exploraram estes recipientes também foi inferior ao observado para os pneus.

Em relação aos períodos estacionais, a ocupação dos recipientes por imaturos de Culicidae concentrou-se principalmente no verão e outono, em praticamente todos os recipientes testados. Durante o inverno foram coletados imaturos de culicídeos apenas nos pneus instalados na área adjacente à mata (Tab. II).

Durante os períodos de outono, primavera e verão as frequências percentuais de positividade para imaturos em pneus no interior da mata atingiram valores próximos. Ainda nos pneus na área adjacente à mata o número mais elevado de positivos ocorreu durante o outono, seguindo em ordem decrescente do verão, primavera e inverno (Tab. II).

A temperatura da água nos recipientes instalados no interior da mata de forma geral atingiu valores inferiores ao alcançado pela temperatura do ar, ou apresentaram valores iguais a temperatura do ar como no caso dos recipientes de lata e plástico, neste último recipiente a temperatura da água chegou a superar em $0,07^{\circ} \mathrm{C}$ a temperatura do ar em única oportunidade (Tab. III).

Os recipientes instalados na área adjacente à mata não apresentaram comportamento homogêneo quanto à temperatura média da água. Nos pneus, a temperatura média da água ao longo das estações do ano foi inferior a do ar, chegando a atingir até $3,92^{\circ} \mathrm{C}$ a menos que a temperatura média do ar, esta ocorrência sendo registrada durante o outono. Por outro lado, nos recipientes de plástico, a temperatura média da água foi superior a do ar durante todos os períodos estacionais, chegando a ser superior à temperatura média do ar em até $4,10^{\circ} \mathrm{C}$, temperatura observada no período do verão (Tab. III). 
Tabela II. Número de ocorrências positivas de culicídeos imaturos e respectivas porcentagens em cada um dos cinco tipos de recipientes instalados, no interior e área adjacente à mata, em cada estação do ano, de março de 1990 a março de 1991, Capão da Imbuia, Curitiba, Paraná.

\begin{tabular}{|c|c|c|c|c|c|c|c|c|c|c|c|c|c|c|c|c|}
\hline \multirow{3}{*}{$\begin{array}{c}\text { Estaçбes } \\
\text { do ano }\end{array}$} & \multicolumn{4}{|c|}{ Cerâmica } & \multicolumn{4}{|c|}{ Cimento-amianto } & \multicolumn{4}{|c|}{ Lata } & \multicolumn{4}{|c|}{ Pneu } \\
\hline & \multicolumn{2}{|c|}{ IM } & \multicolumn{2}{|c|}{$A D$} & \multicolumn{2}{|c|}{ IM } & \multicolumn{2}{|c|}{$A D$} & \multicolumn{2}{|c|}{ IM } & \multicolumn{2}{|c|}{$A D$} & \multicolumn{2}{|c|}{ IM } & \multicolumn{2}{|c|}{$A D$} \\
\hline & $\mathrm{N}$ & $\%$ & $N$ & $\%$ & $\mathrm{~N}$ & $\%$ & $\mathrm{~N}$ & $\%$ & $\mathrm{~N}$ & $\%$ & N & $\%$ & $N$ & $\%$ & $\mathrm{~N}$ & $\%$ \\
\hline Outono $\left(\mathrm{N}^{*}=18\right)$ & 1 & 5,55 & 3 & 16,67 & 2 & 11,11 & 0 & 0,00 & 0 & 0,00 & 3 & 16,67 & 10 & 55,56 & 16 & 88,80 \\
\hline Inverno $\left(\mathrm{N}^{*}=21\right)$ & 0 & 0,00 & 0 & 0,00 & 0 & 0,00 & 0 & 0,00 & 0 & 0,00 & 0 & 0,00 & 0 & 0,00 & 6 & 28,57 \\
\hline Primavera $\left(\mathrm{N}^{*}=18\right)$ & 1 & 5,55 & 0 & 0,00 & 1 & 5,55 & 0 & 0,00 & 0 & 0,00 & 0 & 0,00 & 10 & 55,56 & 10 & 55,56 \\
\hline Verão $\left(N^{*}=21\right)$ & 8 & 38,09 & 1 & 4,76 & 6 & 28,57 & 1 & 4,76 & 1 & 4,76 & 2 & 9,52 & 11 & 52,38 & 12 & 57,14 \\
\hline Total & 10 & 12,82 & 4 & 5,13 & 9 & 11,54 & 1 & 1,28 & 1 & 1,28 & 5 & 6,41 & 31 & 39,74 & 44 & 56,41 \\
\hline
\end{tabular}

(IM) Interior da mata; ( $A D$ ) área adjacente à mata; $(\mathrm{N})$ número de recipientes positivos para imaturos; $\left(\mathrm{N}^{\star}\right)$ número total de recipientes de cada tipo em condições de ser colonizado, por estação e habita; (\%) porcentagem calculada por estação e no total.

Tabela III. Média e desvio padrão da temperatura do ar, no interior e área adjacente à mata, da temperatura da água dos cinco tipos de recipientes artificiais, por estação do ano obtida às 9:00, 12:00 e 15:00 horas, de março de 1990 a março de 1991, Capão da Imbuia, Curitiba, Paraná.

\begin{tabular}{|c|c|c|c|c|c|c|c|c|c|c|c|c|}
\hline \multirow{3}{*}{$\begin{array}{c}\text { Estaçŏes } \\
\text { Horários (h) }\end{array}$} & \multirow{2}{*}{\multicolumn{2}{|c|}{$\begin{array}{c}\text { Temperatura } \\
\text { do } \operatorname{ar}\left({ }^{\circ} \mathrm{C}\right)\end{array}$}} & \multicolumn{10}{|c|}{ Temperatura da água $\left({ }^{\circ} \mathrm{C}\right)$} \\
\hline & & & \multicolumn{2}{|c|}{ Ceramica } & \multicolumn{2}{|c|}{ Cimento-amianto } & \multicolumn{2}{|c|}{ Lata } & \multicolumn{2}{|c|}{ Plástico } & \multicolumn{2}{|c|}{ Pneu } \\
\hline & IM & $A D$ & IM & $A D$ & IM & $A D$ & IM & $A D$ & IM & $A D$ & IM & $A D$ \\
\hline \multicolumn{13}{|l|}{ Outono/90 } \\
\hline 09:00 & $\begin{array}{r}14,83 \\
(5,87)\end{array}$ & $\begin{array}{l}15,72 \\
(5,68)\end{array}$ & $\begin{array}{l}14,58 \\
(5,20)\end{array}$ & $\begin{array}{l}15,30 \\
(5,75)\end{array}$ & $\begin{array}{l}14,58 \\
(5,46)\end{array}$ & $\begin{array}{l}15,80 \\
(5,43)\end{array}$ & $\begin{array}{l}14,67 \\
(5,17)\end{array}$ & $\begin{array}{l}15,70 \\
(5,59)\end{array}$ & $\begin{array}{l}14,67 \\
(5,17)\end{array}$ & $\begin{array}{l}16,50 \\
(5,51)\end{array}$ & $\begin{array}{l}14,17 \\
(5,26)\end{array}$ & $\begin{array}{c}14,70 \\
(5,36)\end{array}$ \\
\hline $12: 00$ & $\begin{array}{r}17,80 \\
(5,25)\end{array}$ & $\begin{array}{l}21,17 \\
(5,16)\end{array}$ & $\begin{array}{l}14,90 \\
(4,93)\end{array}$ & $\begin{array}{c}19,42 \\
(5,87)\end{array}$ & $\begin{array}{l}14,70 \\
(5,43)\end{array}$ & $\begin{array}{c}19,87 \\
(5,94)\end{array}$ & $\begin{array}{r}14,90 \\
(5,20)\end{array}$ & $\begin{array}{l}20,00 \\
(5,05)\end{array}$ & $\begin{array}{l}15,00 \\
(5,00)\end{array}$ & $\begin{array}{l}22,17 \\
(5,79)\end{array}$ & $\begin{array}{r}14,80 \\
(5,23)\end{array}$ & $\begin{array}{l}17,25 \\
(5,34)\end{array}$ \\
\hline $15: 00$ & $\begin{array}{c}19,67 \\
(3,87)\end{array}$ & $\begin{array}{l}21,70 \\
(4,39)\end{array}$ & $\begin{array}{l}16,58 \\
(4,32)\end{array}$ & $\begin{array}{l}21,58 \\
(6,59)\end{array}$ & $\begin{array}{l}16,17 \\
(4,61)\end{array}$ & $\begin{array}{l}21,75 \\
(6,41)\end{array}$ & $\begin{array}{l}16,50 \\
(4,36)\end{array}$ & $\begin{array}{l}21,83 \\
(5,82)\end{array}$ & $\begin{array}{l}16,50 \\
(4,36)\end{array}$ & $\begin{array}{l}22,96 \\
(5,69)\end{array}$ & $\begin{array}{l}16,58 \\
(4,32)\end{array}$ & $\begin{array}{l}18,54 \\
(4,69)\end{array}$ \\
\hline \multicolumn{13}{|l|}{ Inverno/90 } \\
\hline 09:00 & $\begin{array}{l}10,71 \\
(4,91)\end{array}$ & $\begin{array}{l}11,37 \\
(4,74)\end{array}$ & $\begin{array}{l}10,28 \\
(3,77)\end{array}$ & $\begin{array}{l}10,23 \\
(2,98)\end{array}$ & $\begin{array}{l}10,21 \\
(4,02)\end{array}$ & $\begin{array}{l}11,14 \\
(2,94)\end{array}$ & $\begin{array}{l}10,71 \\
(3,54)\end{array}$ & $\begin{array}{l}11,14 \\
(3,14)\end{array}$ & $\begin{array}{l}10,78 \\
(3,53)\end{array}$ & $\begin{array}{l}11,43 \\
(3,11)\end{array}$ & $\begin{array}{c}9,71 \\
(3,64)\end{array}$ & $\begin{array}{l}10,21 \\
(3,13)\end{array}$ \\
\hline $12: 00$ & $\begin{array}{l}12,14 \\
(4,53)\end{array}$ & $\begin{array}{l}13,61 \\
(5,11)\end{array}$ & $\begin{array}{l}10,71 \\
(3,35)\end{array}$ & $\begin{array}{l}13,08 \\
(3,13)\end{array}$ & $\begin{array}{l}10,64 \\
(3,37)\end{array}$ & $\begin{array}{l}13,82 \\
(3,56)\end{array}$ & $\begin{array}{l}11,14 \\
(3,17)\end{array}$ & $\begin{array}{l}13,36 \\
(3,19)\end{array}$ & $\begin{array}{l}11,14 \\
(3,17)\end{array}$ & $\begin{array}{l}14,89 \\
(3,41)\end{array}$ & $\begin{array}{l}10,57 \\
(3,29)\end{array}$ & $\begin{array}{l}12,14 \\
(2,81)\end{array}$ \\
\hline $15: 00$ & $\begin{array}{l}13,64 \\
(4,43)\end{array}$ & $\begin{array}{l}14,60 \\
(4,91)\end{array}$ & $\begin{array}{l}11,57 \\
(3,05)\end{array}$ & $\begin{array}{l}15,00 \\
(3,96)\end{array}$ & $\begin{array}{l}11,57 \\
(3,05)\end{array}$ & $\begin{array}{l}15,71 \\
(4,23)\end{array}$ & $\begin{array}{l}11,71 \\
(2,93)\end{array}$ & $\begin{array}{l}15,25 \\
(3,75)\end{array}$ & $\begin{array}{l}12,00 \\
(3,17)\end{array}$ & $\begin{array}{l}16,36 \\
(4,03)\end{array}$ & $\begin{array}{l}11,50 \\
(3,20)\end{array}$ & $\begin{array}{l}13,21 \\
(3,14)\end{array}$ \\
\hline \multicolumn{13}{|l|}{ Primavera/90 } \\
\hline 09:00 & $\begin{array}{l}18,83 \\
(3,61)\end{array}$ & $\begin{array}{l}20,98 \\
(4,28)\end{array}$ & $\begin{array}{l}17,25 \\
(3,06)\end{array}$ & $\begin{array}{l}19,83 \\
(3,48)\end{array}$ & $\begin{array}{r}17,33 \\
(3,14)\end{array}$ & $\begin{array}{l}19,96 \\
(3,46)\end{array}$ & $\begin{array}{l}17,33 \\
(3,03)\end{array}$ & $\begin{array}{l}20,08 \\
(3,75)\end{array}$ & $\begin{array}{l}17,00 \\
(3,26)\end{array}$ & $\begin{array}{l}21,37 \\
(3,88)\end{array}$ & $\begin{array}{l}16,75 \\
(3,43)\end{array}$ & $\begin{array}{l}18,96 \\
(3,67)\end{array}$ \\
\hline $12: 00$ & $\begin{array}{l}22,00 \\
(4,29)\end{array}$ & $\begin{array}{l}23,93 \\
(4,92)\end{array}$ & $\begin{array}{c}18,17 \\
(3,06)\end{array}$ & $\begin{array}{l}23,75 \\
(5,14)\end{array}$ & $\begin{array}{r}18,25 \\
(3,22)\end{array}$ & $\begin{array}{l}24,04 \\
(5,01)\end{array}$ & $\begin{array}{l}18,08 \\
(3,01)\end{array}$ & $\begin{array}{l}23,21 \\
(5,49)\end{array}$ & $\begin{array}{l}18,00 \\
(3,53)\end{array}$ & $\begin{array}{l}26,92 \\
(5,32)\end{array}$ & $\begin{array}{l}17,92 \\
(3,17)\end{array}$ & $\begin{array}{l}21,00 \\
(3,90)\end{array}$ \\
\hline $15: 00$ & $\begin{array}{l}23,00 \\
(4,94)\end{array}$ & $\begin{array}{l}23,82 \\
(5,62)\end{array}$ & $\begin{array}{l}18,83 \\
(3,19)\end{array}$ & $\begin{array}{l}24,25 \\
(4,96)\end{array}$ & $\begin{array}{l}19,08 \\
(3,28)\end{array}$ & $\begin{array}{l}25,75 \\
(5,09)\end{array}$ & $\begin{array}{l}19,00 \\
(3,16)\end{array}$ & $\begin{array}{l}26,08 \\
(5,67)\end{array}$ & $\begin{array}{l}18,60 \\
(3,36)\end{array}$ & $\begin{array}{l}27,42 \\
(4,71)\end{array}$ & $\begin{array}{l}18,83 \\
(3,14)\end{array}$ & $\begin{array}{l}21,62 \\
(3,55)\end{array}$ \\
\hline \multicolumn{13}{|l|}{ Verăo/90-91 } \\
\hline 09:00 & $\begin{array}{r}19,83 \\
(1,72)\end{array}$ & $\begin{array}{l}21,62 \\
(1,65)\end{array}$ & $\begin{array}{l}18,25 \\
(1,21)\end{array}$ & $\begin{array}{l}21,16 \\
(1,89)\end{array}$ & $\begin{array}{l}18,08 \\
(1,43)\end{array}$ & $\begin{array}{l}21,04 \\
(1,47)\end{array}$ & $\begin{array}{r}18,25 \\
(1,17)\end{array}$ & $\begin{array}{l}21,83 \\
(2,09)\end{array}$ & $\begin{array}{r}18,50 \\
(1,09)\end{array}$ & $\begin{array}{l}21,12 \\
(6,03)\end{array}$ & $\begin{array}{l}18,00 \\
(1,41)\end{array}$ & $\begin{array}{l}20,04 \\
(1,25)\end{array}$ \\
\hline $12: 00$ & $\begin{array}{l}22,33 \\
(1,54)\end{array}$ & $\begin{array}{l}24,27 \\
(1,65)\end{array}$ & $\begin{array}{l}19,17 \\
(1,17)\end{array}$ & $\begin{array}{l}24,25 \\
(3,10)\end{array}$ & $\begin{array}{l}18,83 \\
(1,29)\end{array}$ & $\begin{array}{l}24,87 \\
(2,32)\end{array}$ & $\begin{array}{l}19,17 \\
(1,17)\end{array}$ & $\begin{array}{l}24,92 \\
(3,31)\end{array}$ & $\begin{array}{l}19,00 \\
(0,89)\end{array}$ & $\begin{array}{l}28,37 \\
(2,21)\end{array}$ & $\begin{array}{l}18,83 \\
(1,29)\end{array}$ & $\begin{array}{l}22,25 \\
(1,08)\end{array}$ \\
\hline $15: 00$ & $\begin{array}{l}24,83 \\
(2,04)\end{array}$ & $\begin{array}{l}26,77 \\
(2,64)\end{array}$ & $\begin{array}{l}20,17 \\
(0,75)\end{array}$ & $\begin{array}{l}26,16 \\
(3,35)\end{array}$ & $\begin{array}{l}19,83 \\
(0,98)\end{array}$ & $\begin{array}{l}28,71 \\
(3,21)\end{array}$ & $\begin{array}{l}20,08 \\
(0,80)\end{array}$ & $\begin{array}{l}28,21 \\
(2,81)\end{array}$ & $\begin{array}{l}19,58 \\
(0,73)\end{array}$ & $\begin{array}{l}30,00 \\
(2,31)\end{array}$ & $\begin{array}{l}19,75 \\
(0,76)\end{array}$ & $\begin{array}{l}23,37 \\
(1,35)\end{array}$ \\
\hline
\end{tabular}

(IM) Interior da mata, $(A D)$ área adjacente à mata. Números entre parênteses indicam desvio padrão da média. 
A temperatura média da água nos recipientes de lata e cimento-amianto, na área adjacente à mata, superou a temperatura média do ar em valores relativamente próximos durante os períodos estacionais. $\mathrm{O}$ valor máximo para o primeiro tipo de recipiente foi de $2,26^{\circ} \mathrm{C}$, enquanto no cimento-amianto a temperatura média da água elevou-se em $1,94^{\circ} \mathrm{C}$ em relação a temperatura média do ar. Estes valores foram registrados para os recipientes de lata durante a primavera, e nos de cimento-amianto durante o verão (Tab. III).

Já nos recipientes de cerâmica, também instalados na área adjacente à mata, a temperatura média da água superou a do ar em no máximo $0,43^{\circ} \mathrm{C}$, valor anotado durante a primavera (Tab. III).

A média do $\mathrm{pH}$ da água dos recipientes de cerâmica, lata, plástico e pneu no interior da mata, resultou em valores de $\mathrm{pH}$ ácido muito próximo da neutralidade. Já nos recipientes de cimento-amianto apresentaram média do $\mathrm{pH}$ com valor distanciando-se da neutralidade no sentido de valor de $\mathrm{pH}$ básico (Tab. IV).

Tabela IV. Média e desvio padrão das vinte e sete amostras dos fatores pH e turbidez (UNT), coletados nos cinco tipos de recipientes artificiais, instalados no interior e área adjacente à mata, no período de março de 1990 a março de 1991, Capão da Imbuia, Curitiba, Paraná.

\begin{tabular}{|c|c|c|c|c|c|}
\hline \multirow{2}{*}{$\because$} & \multicolumn{5}{|c|}{ Recipientes artificiais } \\
\hline & Cerâmica & Cimento-amianto & Lata & Plástico & Pneu \\
\hline \multicolumn{6}{|l|}{$\mathrm{pH}$} \\
\hline Interior da mata & $6,67 \pm 0,31 b$ & $7,81 \pm 0,35 a$ & $6,84 \pm 0,35 a$ & $6,53 \pm 0,45 a$ & $6,69 \pm 0,25 a$ \\
\hline $\begin{array}{l}\text { Adjacente à mata } \\
\text { Turbidez }\end{array}$ & $7,19 \pm 0,31 b$ & $9,42 \pm 0,97 b$ & $7,75 \pm 1,05 b$ & $7,38 \pm 0,99 b$ & $8,00 \pm 0,96 b$ \\
\hline Interior da mata & $2,09 \pm 1,17 a$ & $2,90 \pm 4,69 a$ & $1,47 \pm 1,00 a$ & $1,99 \pm 1,98 a$ & $4,19 \pm 11,23 a$ \\
\hline Adjacente à mata & $14,53 \pm 9,89 b$ & $9,79 \pm 10,75 b$ & $25,56 \pm 17,16 b$ & $13,56 \pm 7,17 b$ & $11,78 \pm 7,43 b$ \\
\hline
\end{tabular}

Letras diferentes na coluna em relação a cada um dos fatores analisados na mesma coluna, indicam diferença significativa a 5,00\%.

$\mathrm{Na}$ área adjacente à mata, em todos os cinco tipos de recipientes introduzidos, a média do $\mathrm{pH}$ durante o período de estudo foi superior ao mesmo tipo em relação ao interior da mata, com valores básicos de $\mathrm{pH}$. No recipiente de cimento-amianto $\mathrm{o} \mathrm{pH}$ da água determinado apresentou-se mais fortemente básico do que $\mathrm{opH}$ determinado no mesmo tipo de recipiente no interior da mata, e em relação aos demais tipos de recipientes instalados na área adjacente a mata (Tab. IV).

Pela comparação, as médias de $\mathrm{pH}$ das vinte e sete coletas entre os recipientes artificiais do mesmo tipo introduzidos no interior e área adjacente à mata apresentaram diferença significativa a nível de 5,00\% (Tab. IV).

De forma geral, as oscilações de $\mathrm{pH}$, a longo do período de estudo foram reduzidas para os recipientes de diferentes constituições tanto no interior como na área adjacente à mata.

Quanto ao fator turbidez da água, a análise de variância entre os níveis determinados nos recipientes do mesmo tipo instalados no interior e área adjacente à mata resultou em diferença significativa a nível de 5,00\%. Entre os cinco tipos de recipientes introduzidos no interior de mata, os valores da média da turbidez apresentaram valores aproximados, com distanciamento maior do recipiente de 
pneu no qual a média da turbidez da água atingiu 4,19 UNT $( \pm 11,23)$, com fortes oscilacões durante o período de estudo (Tab. IV).

O comportamento relativo da turbidez da água entre os cinco tipos de recipentes na área adjacente à mata mostrou-se razoavelmente diferenciado, com as maiores oscilações sendo detectadas nos recipientes de lata e cimento-amianto, enquanto o valor mais elevado de turbidez da água detectado no primeiro recipiente (Tab. IV).

As espécies Culex acharistus, Culex eduardoi, Culex grupo coronator e Toxorhynchites theobaldi, foram coletadas em número e frequência reduzida. $C$. acharistus e C. eduardoi, ocorreram nos mesmos recipientes no interior da matacerâmica, cimento-amianto e pneu - assim como durante o mesmo período estacional verão. Também no período de verão e no interior da mata, foram detectados os imaturos de T. theobaldi, explorando somente os pneus.

Imaturos de Culex grupo coronator, foram coletados nos recipientes de cerâmica e lata instalados na área adjacente à mata e nos pneus em ambos habitats analisados. Nos dois primeiros recipientes citados em número aproximadamente semelhante, respectivamente 40 e 50 imaturos durante o outono. Enquanto nos pneus 39 imaturos no interior da mata e 7 na área adjacente, ambas ocorrências durante a primavera.

Dentre as vinte e sete coletas realizadas nos pneus, foram detectados imaturos de Culex quinquefasciatus em 55,55\% das coletas no interior da mata e 81,48 $\%$ naquelas realizadas na área adjacente à mata. Esta espécie apresentou a maior frequência quantitativa para ambos habitats em relação às demais espécies coletadas nos pneus, atingindo $94,59 \%$ dos imaturos coletados no interior da mata e $99,96 \%$ dos imaturos na área adjacente à mata.

A ausência de imaturos de Culex quinquefasciatus no interior da mata coincidiu com o período no qual a temperatura média mínima do ar para o período imediatamente precedente à coleta atingiu na maior parte das amostragens valores inferiores a $10,0^{\circ} \mathrm{C}$, enquanto a temperatura média máxima do ar oscilou entre aproximadamente $15,0^{\circ} \mathrm{C}$ e $22,0^{\circ} \mathrm{C}$ (Fig. 5).

$\mathrm{Na}$ área adjacente à mata, os imaturos de Culex quinquefasciatus não foram mais coletados a partir da coleta na qual a temperatura média miníma para o período imediatamente precedente a coleta atingiu $4,7^{\circ} \mathrm{C}$. $\mathrm{O}$ número de larvas voltou a crescer quando a temperatura média mínima superou os $10,0^{\circ} \mathrm{C}$. De modo geral neste habitat, as coletas positivas para Culex quinquefasciatus ocorreram sob temperaturas inferiores às observadas no interior da mata (Fig. 5).

Em relação aos períodos estacionais, no interior da mata foram coletados percentuais semelhantes de imaturos durante o outono, primavera e verão. Já na área adjacente à mata houve predominío do outono com $52,52 \%$ das larvas de Culex quinquefasciatus coletadas nesta estação, ressaltando-se o fato da presença de imaturos nas primeiras coletas do inverno, contrastando com ausência de imaturos nos pneus instalados no interior da mata (Fig. 6).

No interior da mata, a média do $\mathrm{pH}$ da água dos pneus independentemente de serem positivos ou negativos para presença de imaturos de Culex quinquefasci- 
atus foi igual a $6,69( \pm 0,25)$, já a média do $\mathrm{pH}$ da água dos recipientes que efetivamente abrigaram imaturos desta espécie foi de $6,16( \pm 0,31)$ com valor minímo de 6,2 e máximo de 7,5.
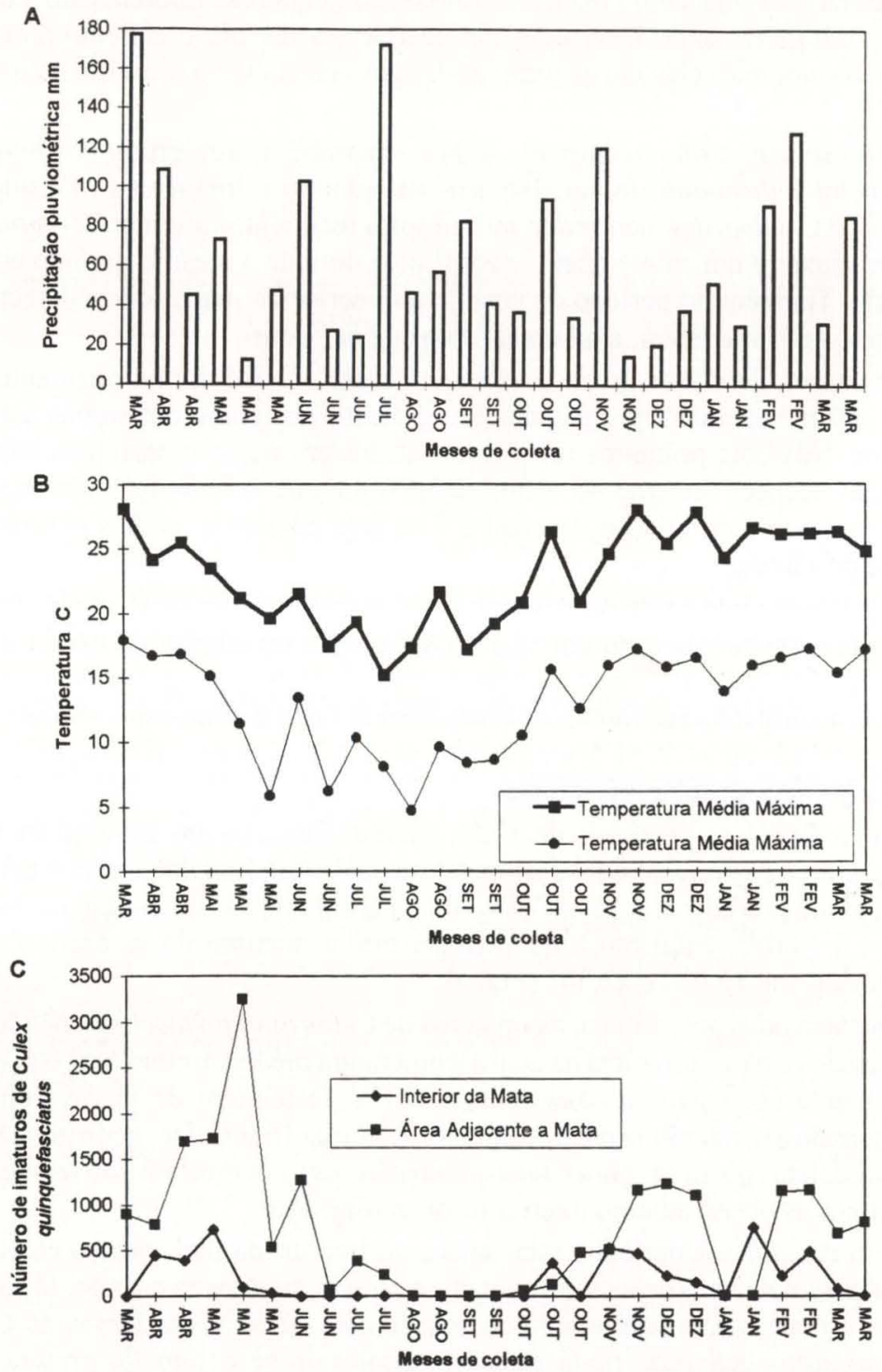

Fig. 5. (A) Precipitação pluviométrica acumulada entre duas coletas sucessivas; (B) temperaturas médias máximas e mínimas, entre duas coletas sucessivas; $(C)$ número de imaturos de Culex quinquefasciatus coletados nos pneus instalados no interior e área adjacente à mata, de março de 1990 a março de 1991, Capão da Imbuia, Curitiba, Paraná. 


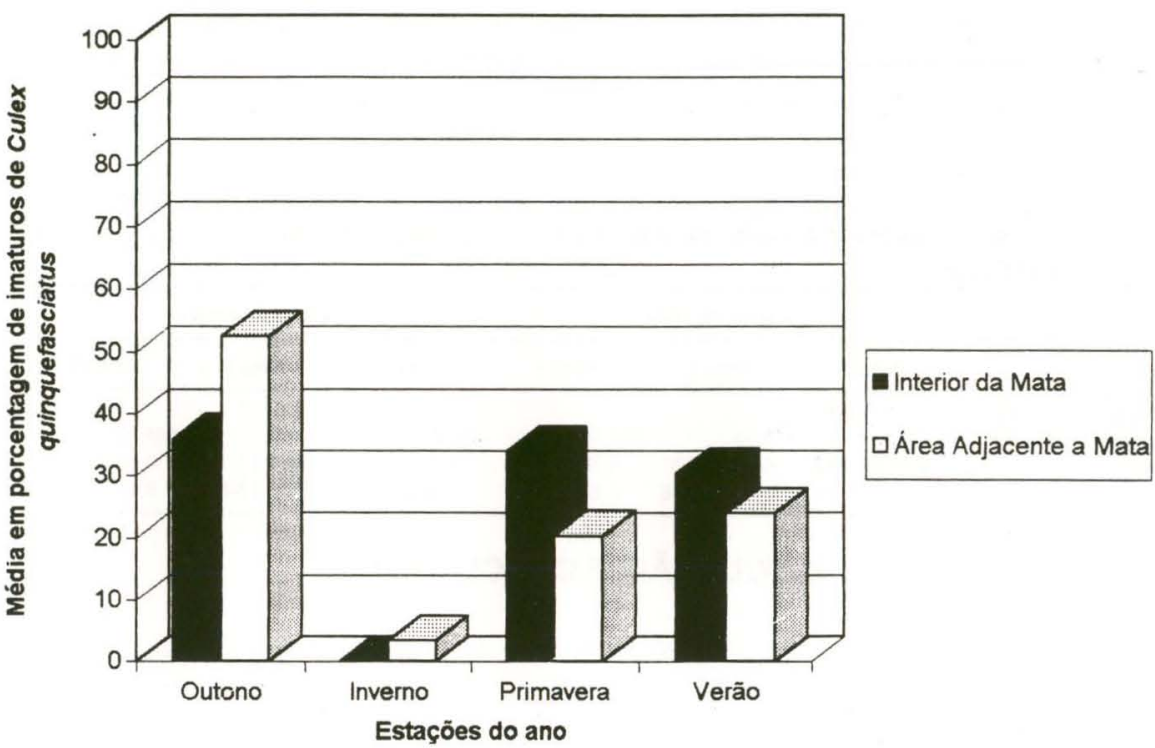

Fig. 6. Porcentagem das médias de imaturos de Culex quinquefasciatus, por estação para cada um dos ecótopos nos pneus instalados no interior e área adjacente à mata, de março de 1990 a março de 1991, Capão da Imbuia, Curitiba, Paraná.

Para área adjacente à mata, a média do $\mathrm{pH}$ da água dos pneus positivos foi de 7,68 $( \pm 0,96)$ com valores oscilando entre 6,5 a 10,8 enquanto o valor da média do $\mathrm{pH}$ da água dos pneus que abrigaram ou não imaturos de Culex quinquefasciatus foi levemente superior, $8,00( \pm 0,96)$. Observou-se neste habitat que valores de $\mathrm{pH}$, embora muito próximos, resultaram em rendimento bastante diferenciado nas coletas de imaturos desta espécie.

A média da turbidez da água nos pneus positivos para Culex quinquefasciatus, no interior da mata foi de 2,41 UNT $( \pm 4,11)$ com os valores oscilando entre 0,3 a 22,0 UNT. Embora esta amplitude seja elevada, o patamar superior ocorreu em única oportunidade, sendo que as demais amostragens positivas atingiram no máximo 3,3 UNT. Já na área adjacente à mata, a média dos pneus que abrigaram imaturos de Culex quinquefasciatus foi de $12,95 \mathrm{UNT}( \pm 13,73)$, com o menor valor de turbidez positivo para imaturos desta espécie igual a 1,3 UNT e o máximo de 51,0 UNT, sendo que $53,49 \%$ das amostragens positivas oscilaram entre 1,0 a 9,9 UNT.

Os pneus instalados no interior da mata apresentaram comportamento aproximadamente homogêneo, em relação a média de imaturos de Culex quinquefasciatus $\mathrm{e}$ os demais fatores analisados, como $\mathrm{pH}$ e turbidez. Já na área adjacente à mata, houve preferência pelo pneu instalado na terceira coluna, onde coletou-se o maior número relativo de imaturos desta espécie, neste pneu a média de $\mathrm{pH}$ foi inferior aos demais e sua turbidez aproximou-se do valor encontrado no pneu instalado na segunda coluna (Tab. V). 
O pneu mais produtivo na área adjacente à mata, pneu da terceria coluna, estava instalado em local que recebia maior sombreamento do que aquele instalado na primeira coluna, pneu 1 . Neste, a turbidez da água foi de aproximadamente 1,80 vezes mais elevada do que a média do pneu da terceira coluna (Tab. V).

Tabela V. Dados comparativos para cada um dos três pneus instalados no interior da mata e os três na área adjacente à mata, de março de 1990 a março de 1991, Capão da Imbuia, Curitiba, Paraná.

\begin{tabular}{lcccccc}
\hline \multirow{2}{*}{ Médias } & \multicolumn{3}{c}{ Interior da mata } & \multicolumn{3}{c}{ Adjacente à mata } \\
\cline { 2 - 7 } & Pneu 1 & Pneu 2 & Pneu 3 & Pneu 1 & Pneu 2 & Pneu 3 \\
\hline Imaturos de Culex & & & & & \\
quinquefasciatus & 179,42 & 115,75 & 189,10 & 262,76 & 80,37 & 646,00 \\
pH & $6,66 \pm 0,43$ & $6,80 \pm 0,31$ & $6,70 \pm 0,25$ & $8,16 \pm 1,07$ & $8,37 \pm 1,10$ & $7,60 \pm 0,97$ \\
Turbidez (UNT) & $5,65 \pm 15,78$ & $4,81 \pm 14,38$ & $2,65 \pm 5,14$ & $17,98 \pm 17,00$ & $7,60 \pm 6,64$ & $9,97 \pm 10,20$ \\
\hline
\end{tabular}

\section{DISCUSSÃO E CONCLUSÕES}

Preferências por um determinado tipo de criadouro para oviposição são exibidas por muitas espécies de mosquitos em diferentes tipos de recipientes, de acordo com a localidade (BARKER-HUDSON et al. 1988), assim como a escolha, segundo BENTLEY \& DAY (1989), é o resultado de uma complexa interação entre fatores químicos e físicos, da qual dependerá a sobrevivência dos estágios aquáticos de mosquitos.

O conjunto dos cinco recipientes artificiais introduzidos no interior da mata apresentaram a menor quantidade de culicídeos imaturos, mas com maior diversidade de espécies que os cinco recipientes introduzidos na área adjacente à mata.

Do cojunto dos diferentes tipos de recipientes artificiais testados na presente investigação em iguais condições, o pneu foi o mais produtivo em número de imaturos de culicídeos, representado principalmente por Culex quinquefasciatus, em ambos habitats analisados.

Algumas evidências tornam os pneus importantes sob o aspecto de saúde pública. O fato, de acordo com BOND \& FAY (1969), de possuírem cor escura, temperatura da água no seu interior inferior a outros tipos de recipientes aritificiais e grande capacidade volumétrica tornam este tipo de criadouro um dos mais atrativos e prolíficos para Aedes aegypti, bem como excelente meio de dispersão desta espécie conforme as observações de KEIRANS (1969). NAWROCKI \& GRAIG (1989) também consideraram os pneus como elemento de dispersão para Aedes atropalpus.

Embora os imaturos de Culex quinquefasciatus tenham ocorrido preferencialmente em pneus, tanto no interior da mata como na área adjacente à mata, os demais recipientes introduzidos ofereceram condições similares quanto ao $\mathrm{pH}, \mathrm{com}$ os valores próximos da neutralidade no primeiro habitat e levemente alcalino no segundo, exceção de cimento-amianto no qual os valores de $\mathrm{pH}$ foram mais elevados em relação aos demais recipientes em ambos habitats. De forma geral de acordo com SinHA (1976), LOZOVEI \& LUZ (1976a), CARLSON (1983), ANDRADE (1955) e FERNANDEZ et al. (1986), os valores de pH detectados estavam em condições 
propícia de aceitação por parte das fêmeas, bem como $\mathrm{pH}$ levemente alcalino que predominou nos recipientes na área adjacente à mata, de acordo com CARLSON (1983).

O fator turbidez não apresentou-se como fator preponderante na determinação do nível de ocupação dos recipientes por imaturos de Culex quinquefasciauts, no interior da mata, uma vez que os cinco tipos de recipientes apresentaram níveis semelhantes de turbidez, de forma geral baixos. Já na área adjacente à mata, os níveis de turbidez da água foram mais elevados, ocorrendo variações entre os recipientes do mesmo tipo e entre as médias dos recipientes de cada tipo.

Em investigação realizada apenas com pneus BEIER et al. (1983a) consideraram a turbidez correlacionada positivamente com três espécies de culicídeos: Aedes atropalpus, Aedes triseriatus e Culex restuans.

De forma geral, os valores de $\mathrm{pH}$ e turbidez da água dos recipientes estiveram influenciados mais pelo habitat do que pela constituição dos mesmos. No interior da mata, o pH da água dos recipientes tendeu à neutralidade em consequência de estarem sujeitos à queda de folhas segundo BEIER et al. (1983b), HARAMIS (1984) e FISH \& CARPENTER (1982). Já na área adjacente à mata, a incidência direta de chuvas e insolação permitiu o bom desenvolvimento de algas e níveis minímos de substrato orgânico, determinando diferentes equilíbrios no $\mathrm{pH}$ da água dos recipientes conforme a citação de BEIER et al. (1983a).

No interior da mata os diferentes tipos de recipientes introduzidos estavam sujeitos a menor oscilação da temperatura da água, fornecendo portanto condições mais estáveis para o desenvolvimento das larvas de culicídeos, não sendo relevante a constituição dos recipientes.

Já na área adjacente à mata, em condições de maior insolação do que no interior da mata, os recipientes estavam sujeitos a uma maior oscilação da temperatura da água, onde o escasso volume retido não permite amortecer as mudanças de temperatura na mesma medida que grandes volumes de água como observa MACHADO-ALLISON (1981). Além da diferença de materiais que entram na composição dos recipientes, neste habitat, apresentarem-se como elemento diferencial no comportamento térmico, como no caso do pneu o qual sofre em menor intensidade a ação da temperatura, em contraposição ao material plástico e lata.

Os recipientes de plástico e lata, foram predominantemente negativos para presença de imaturos de Culicidae, onde apresentaram grande amplitude de variação da temperatura da água, na área adjacente à mata, ao longo do dia, o que pode ter influenciado negativamente na exploração destes recipientes como criadouros de culicídeos.

RUEDA et al. (1990) em experimentos de laboratório com Culex quinquefasciatus, obtiveram as maiores taxas de sobrevivência de eclosão da larva até emergência do adulto, entre $20^{\circ} \mathrm{C} \mathrm{a} 30^{\circ} \mathrm{C}$, reduzindo-se drasticamente estas taxas a $15^{\circ} \mathrm{C}$. SHELTON (1973) com larvas da mesma espécie encontrou maior porcentagem de sobrevivência a $23^{\circ} \mathrm{C}$, dentro da faixa encontrada por RUEDA et al. (1990), acrescentando ainda que o desenvolvimento larval não é viável a $35^{\circ} \mathrm{C}$. Por outro lado, sob condições naturais LOZOVEI \& LUZ (1976a) coletaram imaturos daquela espécie entre $0^{\circ} \mathrm{C}$ a $40^{\circ} \mathrm{C}$, nos arredores da cidade de Curitiba. 
Durante o período de estudo, entre as coletas houve uma distribuição razoavelmente homogênea de chuvas, assim como as médias estacionais de precipitação pluviométrica alcançaram valores próximos, com apenas na primavera ocorrendo pequena redução na queda de chuvas. A temperatura por sua vez sofreu forte declínio durante o inverno.

A diminuição no número de imaturos de Culex quinquefascitus, no período de estudo, acompanhou o declínio da temperatura do ar. Durante o inverno no interior da mata não ocorreu imaturos desta espécie, enquanto na área adjacente houve uma forte redução de imaturos de C. quinquefasciatus coletados. Por outro lado, houve maior concentração populacional desta espécie no outono.

De acordo com O'MEARA et al. (1989b), as fêmeas de Culex quinquefasciatus colocam ovos durante todo o ano, inclusive durante o inverno, com preferência para áreas abertas, igualmente ao observado na área do Capão da Imbuia. LOPES (1992) encontrou maiores densidades desta espécie na estação que apresentou em média as maiores temperaturas diárias e os índices de precipitação pluviométrica mais elevados, trabalhando em área do norte do Estado do Paraná, na qual são registradas temperaturas médias superiores às observadas para Curitiba.

O número de imaturos de Culex quinquefasciatus alcançou número diferenciado nas três repetições dos pneus, com predomínio para aquele que recebia maior sombreamento. Em que pese a diferença de posição, como observaram AMERASINGHE \& ALAGODA (1984), após a colocação da água inicial nos recipientes, a qualidade não é controlada decorrendo variação de recipiente para recipiente, o que pode ser minimizado segundo os autores quando é alterada a posição dos recipientes.

Dentre as demais espécies coletadas, ForatTINI (1962) fez referência a Culex acharistus como espécie pouco conhecida, a qual tem preferência por grandes criadouros, sendo encontrada em pântanos. Culex eduardoi foi coletado por LOPES (1992) em número significativo em pneu.

LOZOVEI \& LUZ (1976a) coletaram imaturos de Culex (Culex) grupo coronator em brejo, sulco de rodas, vala de drenagem em água poluídas. Estes tipos de criadouros para esta espécie já haviam sido assinalados por FORATTINI (1965a) e DAVIS (1944). LOPES (1992) coletou esta espécie em reduzida frequência em pneus. SILVA \& LOPES (1985) coletaram imaturos desta espécie em vasos de cemitério, na cidade de Londrina, Estado do Paraná.

A exploração de recipientes artificiais localizados em área sombreada por Toxorhynchites theobaldi foi assinalada como preferencial por RUBIO \& AYESTA (1984), REYES-VILlanUEVA et al. (1987) e RodRigueZ \& REYES-VILlanUEVA (1992). No Panamá GALINDo et al. (1955) encontraram imaturos desta espécie explorando ocos de árvore, preferencialmente ao nível do solo. Ressaltando-se o fato de que este é o primeiro registro de Toxorhynchites theobaldi em recipientes artificiais, na cidade de Curitiba.

AGRAdECIMENTOS. Ao Prof. Dr. Oswaldo Paulo Forattini e a Profa. Dra. Maria Anice Mureb Sallum (Faculdade de Saúde Pública, Universidade de São Paulo) pela confirmação da identificação das espécies de Culicidae. Ao Dr. José Adolpho Klein Pereira (Laboratório Central de Água, SANEPAR, Curitiba, Paraná), pelo auxílio nas análises químicas da água. 


\section{REFERÊNCIAS BIBLIOGRÁFICAS}

AMERASINGHE, F.P. \& T.S.B. AlagodA. 1984. Mosquito oviposition in bamboo traps, with special reference to Aedes albopictus, Aedes novalbopictus and Armigeres subalbatus. Insect Sci. Applic. 5 (6): 493-500.

ANDRADE, R.M. DE. 1955. Observações hidrobiológicas sôbre o Anopheles tarsimaculatus: III. Distribuição, frequencia de ocorrência e densidade relativa de organismos planctônicos em alguns de seus biótopos. Rev. Bras. de Malariol. e Doenças Trop. 4: 443-490.

ANDREADIS, T.G. 1988. A survey of mosquitoes breending in used tire stockfiles in Connecticut. Jour. Amer. Mosq. Control Assoc. 4 (3): 256-260.

BAILEY, D.L.; R.G. JoNES \& P.R. SimMONOS. 1983. Effectts of indigenous Toxorhynchites rutilus rutilus on Aedes aegypti breending in tire dumps. Mosq. News. 43 (1): 33-37.

BARKER-Hudson, P.; R. JONES \& B.H. KAY. 1988. Categorization of domestic breeding habitats of Aedes aegypti (Diptera: Culicidae) in Northern Queesnland, Australia. Jour. Med. Entomol. 25 (3): 178-182.

BARrera-Rodriguez, R.; C.E. Machado-Allison \& L.A. Bulla. 1979. Criaderos, densidad larval y segregacion de nicho en tres Culicidae urbanos (Culex fatigans Wied., C. corniger THEO. y Aedes aegypti L.) en el cemeterio de Caracas. Acta Cient. Venez. 30: 418-424.

BARRERA-Rodriguez, R.; C.E. MACHADO-Allison; L.A. BUlla \& D.R. STRONG. 1982. Mosquitoes and mourmimg in the Caracas Cemetery. Athenna. 6: 250-252.

BAUMGARTNER, D.L. 1988. Suburban accumulations of discarded tires in northeatern Illinois and their associated mosquitoes. Jour. Amer. Mosq. Control Assoc. 4 (4): 500-508.

Beier, J.C.; C. PAtricoski; M. TRAvis \& J. KranzFelder. 1983a. Influence of water chemical and environmental parameters on larval mosquito dynamics in tires. Environ. Entomol. 12 (2): 435-438.

BeIER, J.C.; N. Travis; C.E. PATRICoski \& J. KRANZFELDER. 1983b. Habitat segregation amongo larval mosquitoes (Diptera: Culicidae) in tire yards in Indiana, USA. Jour. Med. Entomol. 20 (1): 76-80.

BENTLEY, M.D. \& J.F. DAY. 1989. Chemical ecology and behavioral aspects of mosquito oviposition. Ann. Rev. Entomol. 34: 401-421.

BonD, H. A. \& R. W. FAY. 1969. Factors influencing Aedes aegypti occurrence in containers. Mosq. News. 29 (1): 113-116.

CARLSON, D.B. 1983. Ovipositional response of Culex quinquefasciatus to southeast Florida wastewater. Mosq. News. 43 (3): 284-287.

ChadeE, D.D.; A. Le Maitre \& N.K. Connell. 1981. The collection of Haemagogus equinus Theobald breeding in household containers in Tobago W.I. Mosq. News. 41 (3): 568-569.

CHAHAD, S. \& A.L. Lozover. 1994. Distribuição sazonal de mosquitos (Diptera: Culicidae) em floreiras do Cemitério Municipal Água Verde, Curitiba, Paraná, Brasil. Arq. Biol. Tecnol. 37 (4): 827-842. 
Craven, R.B.; D. A. Eliason; D.B. Francy; P. Reiter; E.G. Campos; W.L. JAKOB; G.C. SMITH; C.J. BOZZI; C.G. MoORE; G.O. MAUPIN \& T.P. MONATH. 1988. Importation of Aedes albopictus and other exotic mosquito species into the United States in Used tires from Asia. Jour. Amer. Mosq. Control Assoc. 4 (2): 138-142.

CURTIS, C.F. \& R.G. FEACHEM. 1981. Sanitation and Culex pipiens mosquitoes: a briel review. Jour. Trop. Med. Hyg. 84: 17-25.

DARSIE, R.F. JR. 1985. Mosquitoes of Argentina. Part I. Keys for identification of adult females and fourth stage larvae in English and Spanish (Diptera, Culicidae). Mosq. Syst. 17 (3): 154-253.

DAvis, D.E. 1944. Larval habitats fo some Brazilian mosquitoes. Rev. Entomol. $15(1 / 2): 221-235$.

DisPerati, A.A. \& J.S. JunIOR. 1988. Contagem de copas de Pinheiro do Paraná em fotografias áreas verticais $35 \mathrm{~mm}$. V Simpósio brasileiro de sensoriamento remoto, Natal, p. 619-622.

DoMBrowsKi, L.T.D. \& Y.S. KUNIYOSHI. 1967. A vegetação do "Capão da Imbuia" - I. Araucariana Sér. Bot. 1: 1-18.

FERNANDEZ, M. DEL C.M.; J.A.B. LAZCANO \& A.N. ORTEGA. 1986. Influencia de algunos factores abioticos sobre las fluctuaciones de la poblacion larval de Culex quinquefasciatus, Say 1823 (Diptera: Culicidae). Rev. Cubana. Med. Trop. 38 (3): 281-288.

FISH, D. \& S.R. CAPENTER. 1982. Leaf litter and larval mosquito dynamics in tree-hole ecosystems. Ecology 63 (2): 283-288.

Forattini, O.P. 1962. Entomologia Médica. São Paulo, EDUSP, vol. 1, 662p. 1965a. Entomologia Médica. São Paulo, EDUSP, vol. 2, 506p. 1965b. Entomologia Médica. São Paulo, EDUSP, vol. 3, 416p.

Forattini, O.P. \& E.X. RABELlo. 1960. Notas sôbre Culicidae (Diptera). 2- A larva, a pupa e alguns dados biológicos de Aedes (Finlaya) fluviatilis Lutz, 1904. Arq. Fac. Hig. Saúde Pública Univ. São Paulo. 14 (1-2): 87-94.

GAFFIGAN, T.V. \& R.A. WARD. 1985. Index to the second supplemente to "A catalog of the mosquitoes of the world", with corrections and additions (Diptera:Culicidae). Mosq. Syst. 17 (1): 52-63.

GALINDO, P.; S.J. CARPENTER \& H. TRAPIDO. 1955. A contribution to the ecology and biology of tree hole breeding mosquitoes of Panama. Ann. Entomol. Soc. Amer. 48: 158-164.

GeTTMAN, A.D. \& D.W. HALL. 1989. A modification of scrap automobile tires for field studies of artificial container-breeding mosquitoes. Jour. Amer. Mosq. Control Assoc. 5 (3): 439.

HARAMIS, L.D. 1984. Aedes triseriatus: A comparison of density in tree holes vs. discarded tires. Mosq. News. 44 (4): 485-489.

KeIRANS, J.E. 1969. Larval developmente of Aedes aegypti (L.) in used auto tires. Mosq. News. 29 (1): 43-46.

KNIGHT, K.L. \& A.A. StONE. 1977. A catalog of the mosquitoes of the world (Diptera:Culicidae). College Park, Md.. Entom. Soc. Amer. 17 (1): 1-611. 
Lane, J. \& N.L. Cerqueira. 1942. Os sabetíneos da América (Diptera, Culicidae). Arq. Zool. Est. São Paulo 3: 472-849.

LOPES, J. 1992. Ecologia de mosquitos (Diptera: Culicidae) que procriam em criadouros naturais e artificiais em área rural, Londrina e Cambé, Paraná, Brasil. Tese de Doutorado, não publicada, Universidade Federal do Paraná, Curitiba, 235p.

LOPES, J.; J.R. ARIAS \& J.D. Charlwood. 1985a. Estudo ecológico de Culicidae (Diptera) silvestres criando em pequenos recipientes de água em mata e em capoeira no município de Manaus - AM. Ciênc. Cult. 37 (8): 1299-1340.

LoPES, J.; A.M. BorsATO \& M.A. PIRES. 1987. Entomofauna da Mata Godoy. I.Culicidae (Diptera) procriando-se em criadouros artificiais introduzido na mata. Semina, Londrina, 8 (2): 67-69.

Lopes, J.; J.D. Charlwood \& J.R. ARIAS. 1985b. Sobreposição de espécies de Culicidae (Diptera) criando em pequenos recipientes de água em floresta e capoeira no município de Manaus-Am. Rev. Brasil. Biol. 45 (4): 609-613.

Lopes, J.; M.A.N. DA Silva; A.M. Borsato; V.D.R.B. DE OliveIRA \& F.J. DE OLIVEIRA. 1993. Aedes (Stegomyia) aegypti L. e a culicideofauna associada em área urbana da Região Sul, Brasil. Rev. Saúde Pública, São Paulo, 27 (5): 326-333.

LozoveI, A.L. \& E. LuZ. 1976a. Diptera Culicidae em Curitiba e arredores. I. Ocorrência. Arq. Biol. Tecnol., Curitiba, 19: 25-42.

1976b. Diptera Culicidae em Curitiba e arredores. II. Alimentação. Arq. Biol. Tecnol., Curitiba, 19: 43-84.

Luz, E.; J. Consolim; O.C. BArbosa \& P.B. Torres. 1987. Larvas de Anopheles (subgênero Kerteszia) Theobald, 1905 encontradas em criadouros artificiais, no Estado do Paraná, Brasil. Rev. Saúde Pública, São Paulo, 21 (5): 466-468.

MAACK, R. 1981. Geografia Física do Estado do Paraná. Rio de Janeiro, J. Olympio, $2^{\mathrm{a}}$ ed., 450p.

MACHADO-ALlison, C.E. 1981. Ecologia de los mosquitos (Culicidae) II.Larvas Y Pupas. Acta. Biol. Venez. 11 (1): 51-129.

NASCI, R.S. 1988. Biology of Aedes triseriatus (Diptera: Culicidae) developing in tires in Lousiana. Jour. Med. Entomol. 25 (5): 402-405.

NAWROCKI, S.J. \& G.B. GRAIG JR. 1989. Further extension of the range of rock pool mosquito, Aedes atropalpus, via tire breeding. Jour. Amer. Mosq. Control Assoc. 5 (1): 110-114.

O’Meara, G.F.; L.F. Evans JR. \& A.D. GetTman. 1992a. Reduced mosquito production in cemetery vases with copper liners. Jour. Amer. Mosq. Control Assoc. 8 (4): 419-420.

O’Meara, G.F.; A.D. GetTMAn; L.F. Evans JR. \& F.D. SCHEEL. 1992b. Invasion of cemeteries in Florida by Aedes albopictus. Jour. Amer. Mosq. Control Assoc. 8 (1): 1-10.

O'Meara, G.F.O.; V.L. Larson; D.H. Mook \& M.D. Lathan. 1989a. Aedes bahamensis its invasion of both Florida and association with Aedes aegypti. Jour. Amer. Mosq. Control Assoc. 5 (1): 1-5. 
O'Meara, G.F.; F.E. Vose \& D.B. CARLSON. 1989b. Environmental factor influencing oviposition by Culex (Culex) (Diptera: Culicidae) in two types of traps. Jour. Med. Entomol. 26 (6): 528-534.

RACHOU, R.G.; M.M. LIMA \& J.A.F. NETO. 1954. Levantamento preliminar de criadouros de Culex fatigans em Florianópolis (Estado de Santa Catarina). Rev. Bras. Malariol. Doenças tropicais 6: 497-500.

Reyes-Villanueva, F.; M.H. Badil; M.L. Rodriguez-Tovar \& M. VILLARREAL-LEAL. 1987. Oviposition of Toxorhynchites theobaldi in different types of artificial containers in Mexico. Jour. Amer. Mosq. Control Assoc. 3 (4): 651-654.

RodRiguez, A.D. \& F. ReYes-Villanueva. 1992. Comportamiento sexual de Toxorhynchites theobaldi bajo condiciones de laboratório. Southwest. Entomol. 17 (3): 255-260.

RUBIO, Y. \& C. AYESTA. 1984. Laboratory observations on the biology of Toxorhynchites theobaldi. Mosq. News. 44 (1): 86-90.

RuedA, L.M.; K.J. PAtel; R.C. Axtell \& R.E. Stinner. 1990. Temperature-dependent development and survival rates of Culex quinquefasciatus and Aedes aegypti (Diptera: Culicidae). Jour. Med. Entomol. 27 (5): 892-898.

SHELTON, R.M. 1973. The effect of temperatures on development of eight mosquito species. Mosq. News. 33 (1): 1-12.

SILVA, M.A.N. DA \& J. LOPES. 1985. Dados sobre a potencialidade criadoura de Culicidae (Diptera) do Cemitério São Pedro Londrina-Paraná. Semina, Londrina, 6 (3): 133-139.

SinHA, V.P. 1976. Further obervations on the physico-chemical factors of the breeding places of Culex quinquefasciatus Say = fatigans Wied. Mosq. News. 36 (3): 358-360.

WARD, R.A. 1984. Second Suplement to "A Catalog of the Mosquitoes of the World” (Diptera: Culicidae). Mosq. Syst. 16 (3): 229-270.

Recebido em 17.VI.1996; aceito em 20.XII.1996. 